\title{
Research allocations: Should societal concerns drive the research agenda?
}

Published at www.cmaj.ca on May 10

$\mathrm{S}$ trategic research is often positioned as the antithesis of basic research, but some scientists claim the majority of targeted research is still largely driven by the curiosity of researchers. What people don't agree on is whether this is good or bad.

According to Marco Di Buono, director of research at the Heart and Stroke Foundation, granting researchers the freedom to follow their ideas, within health priorities set by funding bodies, is the proper approach to strategic research. If funders are excessively dogmatic in their approach to targeted research, he says, it would serve only to restrict the scientific community, not advance it.

"If you wanted to tackle stroke recovery, for example, you can launch a competition in that area but still allow the ideas to come from the research community instead of pigeon-holing the research into very specific areas," says Di Buono.

Pierre Chartrand, vicepresident of research at the Canadian Institute of Health Research (CIHR), is also an advocate of researcher freedom. Attempts to force researchers to conduct work that doesn't interest them will prove futile, he says.

"Researchers are not mercenaries," says Chartrand. "They will not go in a direction just because of money. They want to pursue their own ideas."

Besides, if there are large health problems facing Canada, researchers will naturally be drawn to them, says
Chartrand. Researchers are problemsolvers at heart, he says, noting that a recent increase in the number of cases of tuberculosis in Canada was followed

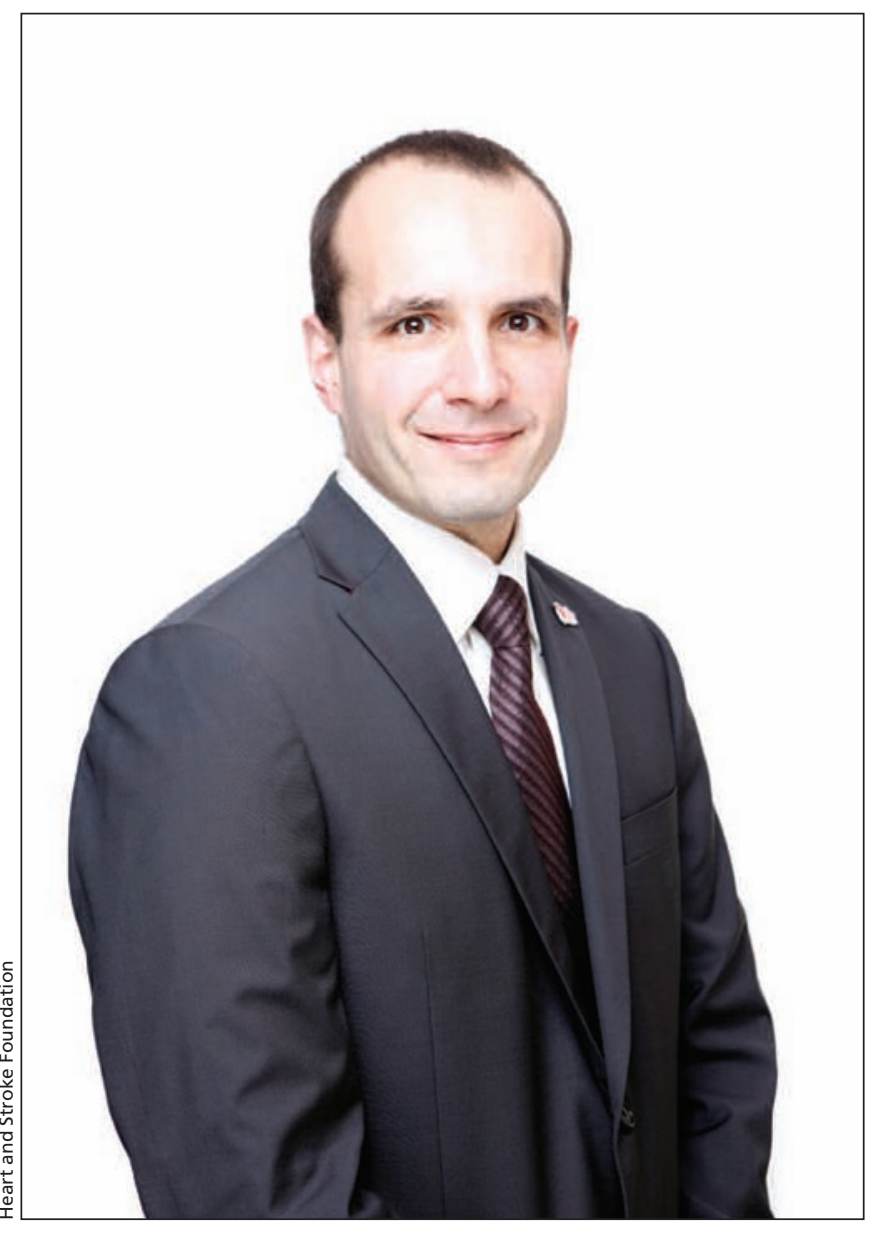

Granting researchers the freedom to follow their ideas, within health priorities set by funding bodies, is the proper approach to strategic research, says Marco Di Buono, director of research at the Heart and Stroke Foundation.

is not a new one. Even politicians have at times advocated for this model. In a 1994 speech to the Association of the American Medical Colleges, former United States Democratic Congressman George E. Brown Jr. said politicians shouldn't tell researchers which experiments to conduct, though this freedom comes at a cost: an obligation to find solutions to societal issues (Acad Med 1994;69:437-40).

"Strategic paths provide the compass; they do not control the journey," wrote Brown. "And science and technology 'in a vacuum' do not constitute a strategic path."

According to the CIHR, the major health problems confronting Canadians include: health inequities faced by Aboriginal communities, effects of climate change on northern populations and the growing burden of chronic diseases in an aging population.

But not everyone is optimistic that problems such as these can be solved if researchers alone decide which studies should be conducted within set priorities.

Roy Cameron, a professor of applied health sciences at the University of Waterloo in Ontario, says he is a big supporter of basic research that is driven by the curiosity of

by an increase in interest about tuberculosis among health researchers.

"People will get interested because there are very important research questions that haven't been answered," says Chartrand.

The concept of using high-level strategic paths to guide medical research, without dictating the details, investigators. But when it comes to strategic research, a more deliberate approach would yield greater results, he says, adding that to effectively address the health needs of Canadians, scientists must generate research that is targeted at shaping public policy.

"If we leave it to investigators to generate that evidence in their own 
time, we miss the window. Politicians will have moved onto other agendas," says Cameron.

Dr. Mark Greenwald, chair of the scientific and medical advisory committee for the Asthma Society of Canada, also wonders if allowing researchers to be guided by their curiosity is the best means of helping Canadians. Canada has excellent researchers in the field of asthma, he says, but some tend to be more interested in solving problems in a laboratory than problems in society, such as workplace absenteeism and degraded quality of life caused by asthma.
“This isn't translated into the average Canadian getting a lot of bang for their buck," says Greenwald.

Private funders of medical research, though, tend to provide more input in steering the direction of targeted research than public funders. Because they rely on private donations, accountability to donors is of high importance. According to Steven McNair, president and chief executive officer of The Arthritis Society, even privately funded basic research should be conducted with societal needs in mind.

"The basic path should lead on the path to strategic science," says McNair.
"That's what donors expect." — Roger Collier, CMAJ

DOI:10.1503/cmaj.109-3244

Third of a series on dividing the research pie.

Part I: Subjective factors often influence outlays (CMAJ 2010. DOI:10.1503/cmaj.109-3238)

Part 2: The long-standing basic/strategic debate (CMAJ 2010. DOI:10.1503/cmaj.109-3241) 